\title{
A relação trabalho e saúde no setor calçadista de Franca, São Paulo
}

\author{
Edvânia Ângela de Souza Lourenço \\ Universidade Estadual Paulista Julio de Mesquita Filho (UNESP), \\ Franca
}

\author{
Iris Fenner Bertani \\ Universidade Estadual Paulista Julio de Mesquita Filho (UNESP), \\ Franca
}

\begin{abstract}
A relação trabalho e saúde no setor calçadista de Franca, São Paulo
Resumo: Este texto busca evidenciar a relação trabalho e saúde em um lócus determinado: a produção calçadista em Franca, interior do estado de São Paulo. A discussão privilegia o processo sócio-histórico da referida atividade econômica em Franca, com ênfase na reestruturação produtiva que, a partir na década de 1990, disseminou parte da produção para as residências dos trabalhadores, constituindo as denominadas Bancas de Pespontos e de Corte em Calçados. Desse modo, a partir do conhecimento empírico, subsidiado pelas visitas a estes empreendimentos e de entrevistas com os trabalhadores e ainda com um relato de caso, enfatiza-se as relações sociais de trabalho que podem agredir à saúde. Todavia, diante da informalidade acabam não sendo consideradas na relação entre saúde e a atividade funcional exercida, ficando estes infortúnios distantes das negociações coletivas, fiscalizações, ou seja, de possíveis mudanças.
\end{abstract}

Palavras-chave: trabalho, reestruturação produtiva, saúde dos trabalhadores.

\section{The Relation of Labor and Health in the Shoe Industry of Franca, São Paulo}

Abstract: This paper analyzes the relation of labor and health at a specific location: the shoe industry of Franca, in the interior of São Paulo State. The discussion emphasizes the socio-historic process of this economic activity in Franca, with an emphasis on the productive re-structuring which, since the 1990s, passed part of the production to the workers' residences, establishing so-called Shoe Stitching and Cutting Groups. In this way, based on empiric research, supported by visits to these establishments, interviews with workers and through presentation of a case study, the paper presents the social relations of labor that can aggravate health. Nevertheless, healthcare is not considered in these informal labor relations and the unfortunate workers involved remain distant from collective bargaining and labor inspections and thus possible change.

Key words: labor, productive restructuring, worker health. 


\section{Por que discutir a relação trabalho e saúde?}

Acredita-se que a nocividade do trabalho não lhe é imbuída naturalmente, machucar ou adoecer não são atributos intrínsecos ao trabalho. Ao contrário, o trabalho é a objetivação do ser humano, momento de criação, de relação homem-natureza-homem, de aprendizado/transformação e de relação social (MARX, 2006). Mas, na sociedade capitalista, o processo e a organização do trabalho, a partir da exploração e espoliação do trabalhador, tende a transformar esta capacidade de criação em mercadoria/objeto.

Marx (2004) demonstrou que o trabalho, mediador orgânico do homem com a natureza, na sociedade capitalista, é marcado pela alienação e estranhamento. O homem é reduzido a sua condição de força de trabalho, ou seja, mercadoria permutável na sociedade salarial. Subordinado aos interesses de quem a compra, o trabalho acaba conformando um grau de extrema negatividade para a realização humano-genérica.

Portanto, as análises de saúde do trabalhador não podem desconsiderar que o processo de desgaste físico e mental é histórico e social (LAURELL; NORIEGA, 1989).

O termo agravos à saúde do trabalhador é utilizado neste artigo, por ser considerado mais amplo, uma vez que abrange tanto os acidentes e doenças típicas, quanto as consideradas atípicas e também o processo de adoecimento.

$\mathrm{O}$ adoecimento é uma agressão à saúde e se revela mais pelos aspectos de ordem subjetiva, sem exteriorizações físicas importantes. É um processo que evidencia que algo não vai bem, nem sempre seguido de uma doença propriamente dita, apesar dos sintomas (RIBEIRO; RUIZ; PINTO, 2007). Além da imprecisão técnico-científica para seu reconhecimento, o processo do adoecimento não deixa de representar um desgaste que, longe de ser passageiro, tem se tornado um estágio para maiores complicações da saúde, com repercussões de ordem social e emocional, temporárias ou permanentes.

Historicamente, os acidentes de trabalho são representados por danos visíveis e, em decorrência, reconhecidos como provenientes do trabalho. As doenças, gradativamente, foram consagradas como objeto de reparação ao lesionado e de intervenção nos ambientes de trabalho (RIBEIRO, 1999), em especial, aquelas tipificadas como doenças clássicas dos trabalhadores (saturnismo, silicose etc.). Entretanto, muitos agravos apesar de estarem intrinsecamente relacionados ao trabalho ainda encontram muitas dificuldades de serem reconhecidos como tal. Fazem parte desse grupo as mortes por exaustão, as Lesões por Esforço Repetitivo (LER), as Doenças Osteomusculares Relacionadas ao Trabalho(DORT) e o sofrimento psíquico.

O reconhecimento de determinadas doenças contou com o envolvimento dos trabalhadores, por exem- plo, as LER dos trabalhadores bancários (RIBEIRO, 1999) e dos digitadores (ASSUNÇÃO; ROCHA, 1993). No caso dos bancários, Ribeiro (1999) explica que isso deriva da capacidade de organização da categoria, dos estudos e envolvimento com a problemática. Alerta o autor também que se trata de uma categoria de diferenciado grau de escolaridade e estrato social, bem como de história de luta e poder de negociação. Assunção e Rocha (1993, p. 468) enfatizam o papel das associações profissionais na discussão e enfrentamento das LER, inclusive destacam que foi um membro da CIPA, de um Centro de Processamento de Dados de um Banco, “[...] que, a partir de uma abordagem epidemiológica, percebeu um grande número de digitadores que apresentavam o braço engessado, passando a questionar a relação das condições de trabalho com o fato."

O reconhecimento da problemática das LER na categoria dos bancários se deu na década de 1980, mas só na década seguinte foi reconhecida como um problema coletivo (RIBEIRO, 1999). Diferentemente do mundo fabril, onde sobressai a teoria dos riscos físicos, químicos etc. como geradores de doenças, nos serviços, no caso, nos bancos, o ambiente de trabalho é limpo, organizado, com temperatura fresca, mesmo que artificial. Portanto, o autor defende que a análise das doenças relacionadas ao trabalho deve se atentar mais para a organização e gestão do trabalho, sujeição hierárquica, inclusive de gênero, e as imposições dentro e fora do ambiente de trabalho do que para a dimensão dos fatores de riscos como causalidade dos agravos.

Trata-se de compreender a problemática não como resultante dos instrumentos de trabalho e, por vezes, dos recursos tecnológicos, pois “A patogenia não está neles, mas na sua apropriação, incorporação e uso, e também na inerente reorganização do trabalho que o patronato impõe e as gerências e chefias administram [...]" (RIBEIRO, 1999, p. 95). A nova gestão do trabalho que intensifica os ritmos de trabalho, cobranças e, ainda, os salários associados ao cumprimento de metas, implica em maiores tensões, angústias e estresses.

\section{Metodologia}

Este estudo está subsidiado na proposta de atuação em conjunto com o Sindicato dos Trabalhadores do segmento dos sapateiros em mapear as condições de trabalho nas Bancas ${ }^{1}$ em Franca. As visitas vêm sendo feitas em dois bairros: Jardim Tropical I e Aeroporto II. Foram realizadas visitas às Bancas de algumas ruas do bairro Jardim Tropical I e entrevistas com os trabalhadores (LOURENÇO; BERTANI, 2008). Para esta discussão, privilegia-se a análise de um relato de caso, colhido a partir de entrevista semiestruturada, realizada em fevereiro de 2009, com o devido consentimento da entrevistada, conforme Ter- 
mo de Consentimento Livre e Esclarecido. O projeto foi devidamente submetido ao Comitê de Ética em Pesquisa da UNESP, onde recebeu parecer favorável, e observou as normas legais e éticas para pesquisa que envolve seres humanos ${ }^{2}$.

Objetiva-se evidenciar o processo de agravo à saúde no setor calçadista, com ênfase para a discussão mais geral do desenvolvimento deste setor e a possível relação entre o processo de trabalho nas Bancas e o surgimento de problemas de saúde e as dificuldades para esta relação, o denominado nexo causal.

\section{O setor calçadista em Franca: exegese, apogeu e crise}

No Brasil, a estrutura produtiva de calçados pode ser representada em dois polos: Vale dos Sinos $(\mathrm{RS})^{3}$, especializado em calçados femininos e Franca (SP) ${ }^{4}$, em calçados de couro masculino. No estado de São Paulo, duas outras cidades se destacam na produção de calçados: Birigui na linha infantil e Jaú, na feminina. Outros estados como Santa Catarina e Minas Gerais também têm tradição no setor.

Em Franca, apesar dos registros indicarem a produção do tipo mais rústico (sandálias de couro) desde fins do século 19, é a partir de meados do século 20 que a produção calçadista adere aos contornos da organização científica do trabalho e introduz novos incrementos, como a produção em espaço próprio (fábrica), e tecnologias, como a esteira mecânica (NAVARRO, 2006). Mas foi com a política do regime militar para a industrialização e o incentivo para a exportação de matéria prima e produtos manufaturados que o município se consolidou como "polo calçadista" 5 .

A década de 1980 foi marcada pela ascensão do município de Franca como principal produtor de calçados masculinos de couro do país, com ampla expansão do mercado interno e externo e de postos de trabalho. Isso em decorrência das medidas protecionistas do governo à exportação de calçados, que se mantiveram até meados de 1980 (NAVARRO, 2006).

Em 1986, o Plano Cruzado incentivou a formação de microempresas e o consumo interno, repercutindo na produção calçadista em Franca que chegou ao record de 35 milhões de pares. Contudo, esse boom foi tão intenso quanto rápido, pois já no ano seguinte com a falência do Plano Cruzado a produção caiu pela metade, acompanhada pela queda brusca dos postos de trabalho e, em 1990, o déficit foi algo em torno de 16 mil vagas de trabalho (NAVARRO, 2006).

Lara (2007) destaca que a produção de calçados em Franca, em 1984, foi de 32 milhões de pares de calçados, para 34.509 mil postos de trabalho. Do montante produzido, 15 milhões de pares teriam sido destinados ao mercado interno e 16,7 milhões ao externo. Já em nos anos 2000, após a forte crise vivenciada pelo setor na década de 1990, é registrada uma reanimação do setor, quando este teria produzido 32,5 milhões de pares de calçados, porém o número de postos de trabalho teria ficado em 18.925 mil postos. Neste período, houve queda também na participação das vendas ao mercado externo, pois 27 milhões de pares de calçados foram destinados ao mercado interno e apenas 5,5 milhões ao externo.

Observa-se que, apesar de ter sido recuperado o índice da produtividade, não ocorreu o mesmo em relação ao número de postos de trabalho. Isso expressa as características da reestruturação produtiva que no seu movimento contraditório impôs novas tecnologias acompanhadas de novas formas de gestão do trabalho, comumente baseadas na lean production, produção enxuta (ALVES, 2000). Por um lado, passa-se a exigir um trabalhador mais qualificado, capaz de operar máquinas mais sofisticadas, de trabalhar em equipe, de propor alternativas aos problemas internos da produção e dos relacionamentos interpessoais. Por outro lado, expõe grande parte da força de trabalho à insegurança, ao trabalho subcontratado, terceirizado, desqualificado, mal remunerado, desprotegido de qualquer benefício previdenciário ou até mesmo do direito ao trabalho, ou seja, relegando-o ao desemprego.

O Estado brasileiro num contexto de crise, desde a década de 1980, com o fím do "milagre econômico", estrutura mecanismos para efetivar a modernização "conservadora" da produção (industrial e agrícola). Assim, num cenário de recessão e de crise inflacionária, o Estado e sua política econômica se subordinam à economia mundial, no processo de sua financeirização. Tratou-se de "adaptar" as novas regras impostas pelo mercado mundializado - assentado no capital financeiro e na ramificação do sistema bancário e das instituições financeiras, cuja capacidade de rendimento parasitário rápido e expansivo estabeleciam a necessidade de liberalização e desregulamentação do mercado. Essas novas regras vieram acompanhadas das medidas neoliberais - pautadas na privatização das empresas estatais, em especial, as consideradas mais rentáveis, e no desmantelamento das conquistas sociais e trabalhistas (CHESNAIS, 1996).

Com efeito, a abertura econômica acabou repercutindo negativamente sobre a indústria nacional, que, despreparada tecnologicamente, passou a enfrentar extremas dificuldades de competitividade e manutenção no mercado. A abertura econômica e financeira impingiu perdas de estímulos aos investimentos no setor produtivo, aumento do desemprego e vertiginosa orientação de investimentos para a especulação financeira. De modo geral, esses fatores macroeconômicos levaram às mudanças no plano microeconômico que, no setor calçadista, provocou a reorganização da gestão do trabalho e da produção, expressa, especialmente, na terceirização e também na sua relocalização. 
Navarro (2006) destaca que a crise econômica repercutiu no arrocho salarial e implicou em queda no consumo interno de calçados, bem como nas dificuldades de competição intercapitalista. Salienta-se que, na década de 1990, as iniciativas do governo brasileiro quanto à abertura dos mercados ressignificaram as opções de consumo interno. Assim, devido à retração de emprego e salário, o setor investiu mais em calçados populares com preços mais acessíveis, porém ainda com baixa capacidade de concorrência com os calçados recém-chegados da China e dos países asiáticos.

Desse modo, Franca vem perdendo espaço no mercado mundial. O Brasil ${ }^{6}$ aparece em terceiro lugar na produção mundial de calçados precedidos pela China e pela Índia, sendo a China a principal produtora com seu calçado em média $30 \%$ mais barato ${ }^{7}$.

O município de Franca teve uma melhora neste setor, quando em 2004, a produção de 35 milhões de pares de calçados foi superior aos anos de maior produção das duas décadas anteriores, porém, verificase, mais uma vez, que o número de postos de trabalho não acompanhou o aumento da produção e ficou em 19.789 (SINDIFRANCA, 2008).

Machado Neto (2006, p. 68) destaca que a melhora na produtividade do setor se deu "Somente em 2000, dois anos após o fim da paridade cambial, é que [quando] o setor deu início ao processo de recuperação das vendas externas." Seguindo a melhora nas exportações brasileiras, em 2004 houve expansão no volume de calçados exportados que, segundo Machado Neto (2006), foi em torno de $12 \%$ maior em relação a 2003 e que o setor coureiro-calçadista representou 3,5\% do total das exportações do país.

As complexas situações no âmbito nacional - abertura da economia, baixa capacidade tecnológica do parque produtivo francano, Plano Real, entre outras, com destaque para a relocalização geográfica industrial e a terceirização - apresentam-se como motivadoras para a composição do "complexo de reestruturação produtiva" (ALVES, 2000), adotado pelas empresas como estratégia para se manterem no mercado e melhorarem a rentabilidade e a competitividade.

A produção de calçados tem como principal característica o uso intensivo de mão de obra, daí que na busca de maior competitividade no mercado mundial houve a relocalização, transferência da produção, ora de um país para outro, ora de uma região para outra dentro de um mesmo país. Ou seja, o capital muda de $\operatorname{lugar}^{8}$ na busca de reduzir os custos da sua produção, já que se transferir para novos lugares, onde não há tradição do setor, pode ser muito lucrativo à medida que, geralmente, se depara com a baixa especialização dos trabalhadores e da sua organização política, o que implica em menores salários e, portanto, maiores lucros. Neste contexto, como apontado por Lara (2007), nos últimos 30 anos, a produção calçadista foi transferida dos países da Europa e EUA para os países periféricos, já que nestes a força de trabalho tem um valor ínfimo em relação àqueles ${ }^{9}$.

No Brasil, Lara (2007, p. 278) destaca que a relocalização da produção de calçados tem se direcionado para a Região Nordeste, em decorrência do valor pago a força de trabalho. Diz ele: "Enquanto no ano de 2001 o salário do trabalhador no setor de calçados no Sul e Sudeste era de R \$280, no Nordeste era de R \$180. Além disso, os estados também têm lançado programas de incentivos fiscais favorecendo a migração de empresas do Sudeste para o Nordeste. Essa relocalização situou o Nordeste como novo polo produtor de calçados que, segundo Machado Neto (2006, p. 66), apesar da escassez de dados, no ano 2000, "corresponderam a cerca de 14\% do total de calçados exportados pelo Brasil, com destaque para o Ceará, com $11 \%$ do total exportado" 10 .

Além da guerra fisscal, da abundância da força de trabalho, dos baixos salários praticados no Ceará e da ausência de uma classe de trabalhadores organizada e combativa, Machado Neto (2006) destaca que os portos nordestinos apresentam vantagens quanto aos custos, devido à sua proximidade com o mercado norte-americano, importante consumidor do calçado brasileiro ${ }^{11}$. Esses são determinantes para 0 crescimento da produção de calçados no Nordeste, em especial no âmbito de exportação.

Acompanha esse movimento - das empresas calçadistas abrirem filiais ou transferirem a produção para outros Estados - a terceirização da produção. Segundo Lara (2007), a prática de transferir para terceiros parte da produção calçadista não é uma especificidade da atualidade. Porém, a partir de 1990, houve a intensificação deste processo, como estratégia para baratear os custos da produção, eliminando, oficialmente, várias vagas no interior das fábricas. Muitas dessas vagas foram transferidas do ambiente fabril e industrial para as Bancas de Pesponto e de Corte em Calçados.

Franca conta com 760 empresas, sendo que mais de $70 \%$ são microempresas ${ }^{12}$ (SINDIFRANCA, 2008). Deve ser dito ainda que esse número poderia ser muito maior, uma vez que as Bancas de Pesponto e Corte em Calçados, não estão inclusas nesses dados.

No empenho de romper com a falta de dados, buscou-se na Prefeitura Municipal de Franca saber o número de bancas registradas pelo município ${ }^{13}$, mas o registro oficial parece estar muito distante da realidade vivida pelo setor, uma vez que se resume a 19 bancas abertas em 2000; 17, em 2005, e 13 em 2007. A experiência profissional, como assistente social do Centro de Referência em Saúde do Trabalhador (CEREST) de Franca ${ }^{14}$, e também as visitas às bancas no bairro Jardim Tropical I permite inferir que esses dados fornecidos pela Prefeitura Municipal de Franca são totalmente irreais (LOURENÇO, 2009). 
Em muitas bancas visitadas, observou-se nenhuma indicação oficial de tal instalação, embora sua existência seja facilmente reconhecida devido a improvisações nas estruturas das moradias. Ao percorrer as ruas, verifica-se a existência dessas instalações de bancas em garagens, varandas ou em puxados. Nesses locais, o trabalho é informal, em geral, realizado sem garantias trabalhistas e, por sua formatação, distantes da físcalização do poder público o que levou Lara (2007) a denominá-lo de invisível ${ }^{15}$.

As bancas são constituídas em momentos de apogeu da produção, geralmente de março a novembro. Após, podem fechar, já que não há serviço.

\section{As relações sociais de trabalho e a subnoti- ficação das doenças a ele relacionadas}

A partir do depoimento (parcial) que se segue, observa-se o processo de desgaste da saúde provocado pelo trabalho, em especial na função de coladeira de peças. Essa função, com a reestruturação produtiva local, é realizada nas bancas, raramente nas fábricas de calçados, comprovando a desconcentração do trabalho fabril e a sua "pulverização" para as residências dos trabalhadores e em bairros periféricos.

Francis tem 44 anos e trabalhou na função de revisora em fábricas de calçados por mais de 20 anos. Na década de 1990, pela dificuldade em conseguir emprego nas fábricas, passou a trabalhar em bancas, na função de coladeira de peças; está há 7 anos nesta atividade, onde teria desenvolvido tendinite nos membros superiores.

Eu sempre trabalhei duro desde os 9 anos de idade, mas como sapateira foi com 18 anos. Já fiz consertos e fui revisora, mas com a crise foi ficando difícil conseguir emprego e eu comecei a me arranjar nas bancas, como coladeira de peças. É pesado, porque você tem que usar muito as mãos e os braços, é o dia todo passando o pincel de cola, cortando as sobras e batendo o martelo, você puxa e segura a peça, passa a cola e bate o martelo para fixar [...]. Também tem a questão de quando tem serviço, a gente fica até mais tarde para dar conta e no outro dia você entra mais cedo e isso é nos finais de semana e feriados também. Ah, é duro, vai indo você não aguenta, os braços começam a formigar, parece que ficam pesados e doem muito e o pior é que você perde a força e não consegue fazer as coisas como antes [...] a sua produção cai e se o chefe perceber aí você está na rua. O ser humano é bom, tem valor quando tem saúde, se ficar doente é descartado [...] É duro! Eu fui à UBS [Unidade Básica de Saúde] e o médico me encaminhou ao ortopedista [...]. Ele falou que era tendinite, mas não melhorava aí ele me encaminhou para outro médico que disse que era fibromialgia [...]. Eu estou fazendo o tratamento, mas sinto que não posso forçar que aí dói, a noite é pior é difícil dormir. Agora mesmo eu tomei um remédio para ver se melhora a dor. Na perícia eles me liberaram [...]. Tem pouco tempo que eu voltei a pagar o INSS, porque nas bancas eles não registram não. Mas eu estou com as mãos e braços inchados aí eles não me deixaram trabalhar, então eu voltei ao INSS, mas a nova perícia ficou para daqui dois meses e até lá como eu vou viver?

O depoimento evidencia a relação entre o processo de trabalho e a saúde dos trabalhadores; ilustra bem as dificuldades que estes encontram para ter acesso aos direitos previdenciários e, sobretudo, para tratar do seu problema como relacionado ao trabalho. O problema chegou a ser diagnosticado como tendinite que, relaciona-se à repetitividade das tarefas, postura, ausência de pausas, pressão, intensificação do trabalho etc. Depois o caso foi rediagnosticado, prevalecendo a explicação como doença reumática - fibromialgia distanciando-se, assim, da relação com o trabalho e direcionando para a pré-disposição individual das pessoas em desenvolver determinada doença. Desta forma, estabelecem-se verdadeiras barreiras para a abordagem relacionada aos processos de trabalho. Configura-se como uma doença individual e não como de uma classe, que seria passível de mobilização dos trabalhadores e de intervenção pública.

A trabalhadora explica que a função de passar cola, além de monótona, exige maior uso da força das mãos e braços " [...] é o dia todo passando o pincel de cola, cortando as sobras e batendo o martelo, você puxa e segura a peça, passa a cola e bate o martelo para fixar." Durante visitas às bancas, observou-se que as Lesões por Esforço Repetitivo (LER) são queixas comuns deste processo de trabalho. Parece ser comum também o uso de medicamentos por conta própria, uma vez que para suportar a dor e manter a produção, os trabalhadores referiram fazer uso de analgésicos e anti-inflamatórios.

Outros problemas de saúde observados nestes estabelecimentos referem-se à cefaleia, depressão, a dores de estômago e problemas de coluna.

Os ambientes são improvisados, precários quanto às condições de iluminação, organização e conforto, oferecendo várias possibilidades de agressões à saúde, tanto de acidentes quanto de adoecimentos. Há a convivência constante com o cheiro de cola e solventes, o que, segundo os trabalhadores, causa alergias respiratórias e, às vezes, dermatite de contato; houve trabalhadoras que reclamaram de terem adquirido sobrepeso devido ao uso constante de medicamentos antialérgicos.

Há períodos de escassez da produção, quando as bancas ficam ociosas. Há períodos de muito serviço com intensificação do ritmo e da jornada de trabalho: "[...] quando tem serviço, a gente fica até mais tarde 
para dar conta e no outro dia você entra mais cedo e isso é nos finais de semana e feriados também". Nessas ocasiões o período de descanso é insuficiente para a reposição das energias, além de prejudicar o tempo livre do trabalhador.

Outro problema que subjaz a este e está interligado aos demais é o fato do trabalho ser realizado nas próprias residências dos trabalhadores. É difícil separar hora de trabalho e hora de lazer ou de vida doméstica, aliás, como dito, a ampliação da jornada de trabalho por si só já impede o usufrutuo do tempo livre do trabalhador. Não se pode esquecer também da convivência constante com a aspereza do sistema produtivo, expresso no pó do couro, no cheiro de solventes e de cola, no barulho das máquinas, na concentração exigida, na monotonia e repetitividade das tarefas, e nas cobranças impostas. Esses fatores são agressores à saúde. Tudo isso se mistura e se soma ao ambiente familiar, e a afetividade inerente a esse vai sendo substituída pelo ritmo e pela demanda de produção e trabalho. São questões nem sempre mensuráveis, mas que influenciam sobremaneira a qualidade das relações socioafetivas, de trabalho e de saúde.

Observa-se que a entrevistada disse que "[...] Tem pouco tempo que eu voltei a pagar o INSS, porque nas bancas eles não registram não". Ao transferir a produção para as bancas, as firmas se descartam da responsabilidade social e trabalhista com os sujeitos envolvidos nesses processos de trabalho. Nas bancas, predominam as relações familiares e de vizinhança, o que implica na baixa cobrança dos registros em Carteira de Trabalho e na oficialização das relações contratuais, mantendo esses trabalhadores na invisibilidade (LARA, 2007). Portanto, rompe-se com o confronto entre capital e trabalho e se mantém essas relações longe das negociações coletivas.

É sabido que os trabalhadores, vítimas de agravos relacionados ao trabalho, enfrentam um longo percurso para ter acesso aos benefícios previdenciários. Como a entrevistada relatou, ela passou em consulta na Unidade Básica, foi encaminhada ao especialista (ortopedista), depois para outro e mesmo estando com os braços edemaciados não conseguiu “o afastamento pelo INSS". É preciso pensar nos agravos, não apenas a partir da sua ocorrência em si, mas de como a sociedade está organizada para "reparar" a vítima e prevenir e intervir nestes problemas, o que remete à imprecisão do precário sistema de seguro social e também dos serviços de saúde (LOURENÇO; BERTANI, 2007).

Em geral, a vítima de agravos à saúde relacionados ao trabalho ainda enfrenta um quadro de insegurança para conseguir afastamento previdenciário. Além da pressão psicológica sofrida pelo trabalhador a cada vez que é periciado, há de se considerar também o tempo de afastamento que, geralmente, não coincide com o tempo de tratamento e recuperação.
Historicamente, a seguridade social não se posiciona de modo efetivo frente à problemática trabalho e saúde. Apenas com a criação do Nexo Técnico Epidemiológico Previdenciário (NTEP) (BRASIL, 2007) é que houve a inversão de ônus, ou seja, o nexo de individual passa a ser epidemiológico. Dessa maneira, a partir de março de 2007, passou a vigorar o NTEP, o qual promove o reconhecimento das patologias relacionadas ao trabalho, por meio de análises epidemiológicas entre a Classificação Nacional de Atividades Econômicas (CNAE) e a Classificação Internacional de Doenças (CID-10). Com a inversão de ônus, cabe à a empresa provar que proporciona as medidas de saúde e segurança e que o trabalhador não adquiriu o eventual problema em determinado trabalho. Assim, foi instituído que o Fator Acidentário Previdenciário (FAT) possa premiar as empresas com menores índices de adoecimentos, com redução das alíquotas, e cobrar mais daquelas que apresentam maiores índices de agravos. Entre os avanços já efetivados pelo NTEP está o aumento da notificação das LER que tiveram $893 \%$ de aumento nos registros e as doenças psíquicas 1324\%, considerando os anos de 2006 e 2007 (OLIVEIRA, 2008).

O NEPT é um avanço, mas vem encontrando muitos entraves. As empresas, pressionadas pelo possível aumento de alíquota, organizaram-se e estão fechando o cerco no ato das contratações. Os exames admissionais estão mais rigorosos, impondo dificuldades ao ingresso de trabalhadores no mercado formal e, portanto, de serem contemplados pelo NEPT. Além disso, o "complexo de reestruturação produtiva" (ALVES, 2000) é um limite para a efetivação do NTEP. A terceirização da produção e o subemprego representam sérios limites ao nexo epidemiológico, porque compreendem apenas os trabalhadores segurados pelo INSS. Num contexto de desemprego e aumento do subemprego (em tempo parcial, autônomo, domiciliar, informal etc.), muitos problemas de saúde não são registrados ou segurados pela previdência. O processo de doença e adoecimentos se torna fluído, disperso, como o é o trabalho que não se concentra mais em uma grande fábrica, mas se efetiva nas ruas, nos domicílios, nas fabriquetas de fundo de quintal. O que, entre outras dificuldades, afeta o reconhecimento e o registro dos agravos como relacionados ao trabalho.

Deve se considerar, ainda, que a terceirização implica em um deslocamento de informação de onde ocorre o acidente. As notificações dos agravos são feitas, geralmente, no nome da empresa contratante, portanto, apesar do mesmo ter acontecido em determinada empresa, acaba sendo notificado pela empresa (terceira) que o contratou. Juridicamente a responsabilidade é dividida entre a empresa contratante e aquela em que o trabalhador desenvolve as suas 
funções. Entretanto, ao ter o acidente ou a doença reconhecidos pela empresa contratante, pode-se estabelecer a incompreensão da realidade objetiva de trabalho.

Relaciona-se a este sério problema a tradição dos serviços de saúde pública e privada em não notificar os agravos oriundos do trabalho. Soma-se a isso ênfase dos diagnósticos que consideram os problemas como questões individuais, de sintomas ou de comportamentos, mantendo os efeitos agressivos do trabalho, ou da profissão, distantes da relação epidemiológica e, portanto, das mesas de negociações e das possíveis políticas públicas (LOURENÇO, 2008).

\section{Considerações finais}

A individualização dos diagnósticos contribui para o distanciamento do coletivo dos trabalhadores na discussão da relação entre processos, relações sociais de trabalho e saúde. Além das mudanças do mundo do trabalho significarem redução dos empregos formais e das garantias dos direitos sociais e trabalhistas, e de alavancarem os índices de desemprego e subemprego, elas têm implicado, sobretudo, na fragilização da organização política dos sujeitos, que diante das atuais circunstâncias acabam por privilegiar a luta pela garantia do emprego, deixando para um plano posterior as discussões sobre os aspectos qualitativos, inclusive de saúde no e pelo trabalho.

Acredita-se ser preciso trazer à discussão as relações da nova organização da produção com a saúde dos trabalhadores, pois, como referido, a estrutura calçadista em Franca está organizada em mais de $70 \%$ em microempresas. Este fato é uma problemática para a saúde do trabalhador. Salienta-se que nesses ambientes é sempre mais difícil o resguardo dos direitos do trabalho, bem como das políticas de saúde e segurança dos trabalhadores. Ademais, utilizam-se de precárias estruturas e de maquinários obsoletos, intensificando os fatores agressores à saúde. Os riscos de danos ao meio ambiente e à saúde podem ser auto-monitorados pelas grandes empresas, inclusive os das suas prestadoras de serviços, devido necessária preservação da sua imagem no mercado, porém as “[...] as empresas de porte médio ou pequeno, de propriedade nacional e com processos industriais defasados, tenderão a ficar à margem deste mercado. Faltar-lhes-ia a cultura preservacionista e preventivista..." (RIBEIRO et al., 1998, p. 44). Além disso, trata-se de um trabalho sem garantias trabalhistas e previdenciárias.
Por fim, a perspectiva adotada, que considera o papel do processo de trabalho e das relações sociais inerentes no desenvolvimento do agravo, necessita de mais estudos e discussões e, sobretudo, do envolvimento e atuação do movimento sindical e das universidades.

\section{Referências}

ALVES, G. O novo (e precário) mundo do trabalho: reestruturação produtiva e crise do sindicalismo. São Paulo: Boitempo, Fapesp, 2000.

ASSUNÇÃO, A. A.; ROCHA L. E. Agora... até namorar fica difícil: uma história de lesões por esforços repetitivos. In: BUSCHINELLI, T. et al. Isto é trabalho de gente? Vida, doença e trabalho no Brasil. Petrópolis: Vozes, 1993. p. 461-493.

BRASIL. Decreto n. 6.042 de 12 de fevereiro de 2007. Altera o Regulamento da Previdência Social, aprovado pelo Decreto $\mathrm{n}^{\circ} 3.048$, de 6 de maio de 1999, disciplina a aplicação, acompanhamento e avaliação do Fator Acidentário de Prevenção - FAP e do Nexo Técnico Epidemiológico, e dá outras providências. Disponível em: $<$ https://www.planalto.gov.br/ccivil_03/_Ato2007-2010/ 2007/Decreto/D6042.htm>. Acesso em: $5 \overline{\text { dez. }} 2007$.

CHESNAIS, F. A mundialização do capital. São Paulo: Xamã, 1996.

LARA, R. O trabalho invisível em Franca - SP. In: CANÔAS, J. W. (Org.). Nas pegadas do sapateiro: 65 anos do Sindicato dos Trabalhadores da Indústria de Calçados. Franca: UNESP, 2007. p. 233-327.

LAURELL, A. C.; NORIEGA, M. Processo de produção e saúde: trabalho e desgaste operário. São Paulo: Hucitec, 1989.

LOURENÇO, E. Â. de S. O mundo do trabalho adoece. Estudos do Trabalho. Ano II, n. 3, 2008. Disponível em: $<$ http://www.estudosdotrabalho.org/-Artigo EdvaniaAngela.pdf $>$. Acesso em: 28 nov. 2008.

. Na trilha da saúde do trabalhador: a experiência de Franca/SP. 2009. 426 f. Tese (Doutorado) - Programa de Pós-Graduação em Serviço Social da Unesp, campus de Franca, São Paulo, 2009.

LOURENÇO, E. Â. de S.; BERTANI, I. F. A fábrica em casa: precarização do trabalho no setor calçadista em Franca e os reflexos para a saúde dos trabalhadores. 2008. 
Disponível em: <http://www.estudosdotrabalho.org/ anais6seminariodotrabalho/6-seminariotrabalho.htm>. Acesso em: 20 set. 2008.

Saúde do trabalhador no SUS: desafios e perspectivas frente à precarização do trabalho. Revista Brasileira de Saúde Ocupacional, São Paulo, v. 32, n. 115, 2007, p. 121-134, 2007a. Disponível em: <http:// www.fundacentro.gov.br/rbso/-BancoAnexos/ RBSO\%20115\%20Saúde\%20do\%20trabalhador\% 20no\%20SUS.pdf $>$. Acesso em: 12 fev. 2008.

MACHADO NETO, A. J. Os determinantes do comportamento exportador da indústria calçadista francana. 2006. 272 f. Tese (Doutorado em Administração) - Departamento de Administração da Faculdade de Economia, Administração e Contabilidade. Universidade São Paulo, USP, São Paulo, 2006.

MARX, K. O capital: crítica da economia política. Rio de Janeiro: Civilização Brasileira, 2006. (livro I).

. Manuscritos econômicos filosóficos. São Paulo: Boitempo, 2004.

MURTA, A. Desemprego deve aumentar nos EUA. Dez. 2008. Disponível em: <http://www.ihu.unisinos.br/ index.php? option=com_noticias\&Itemid= $18 \&$ task $=$ detalhe $\& \mathrm{id}=18728>$. Acesso em: dez. 2008.

NAVARRO, V. L. Trabalho e trabalhadores do calçado. A indústria calçadista de Franca: das origens artesanais à reestruturação produtiva. São Paulo: Expressão Popular, 2006.

OLIVEIRA, C. No limite da razão: afastamentos por distúrbios mentais relacionados ao trabalho aumentaram 260 por cento nos últimos seis anos. Revista Proteção, n.199, v. 21, p. $38-53$, jun. 2008.

RIBEIRO, H. P. et al. Projeto de políticas e práticas na área de saúde do trabalhador para o Estado de São Paulo. Relatório I: diagnóstico de situação e propostas, 1998. Fotocopiado.

RIBEIRO, H. P. A violência oculta do trabalho: as lesões por esforços repetitivos. Rio de Janeiro: Fiocruz, 1999.

; RUIZ, R.; PINTO, N. As doenças dos trabalhadores: uma saga mal contada. São Paulo: Unifesp, 2007. (Curso de extensão: doenças e adoecimentos do trabalho contemporâneo). Fotocopiado.

SINDIFRANCA - Sindicato da Indústria de Calçados de Franca. Informações gerais sobre o setor calçadista. Disponível em: <http:/www.sindifranca.org.br/arquivos/ 1224164186_Resenha-Estatistica-Setembro-2008.xls>. Acesso em: $2 \overline{3}$ set. 2008.

\section{Notas}

1 “As Bancas são unidades produtivas (oficinas de trabalho) que prestam serviços à indústria e seu porte é variado: há aquelas que contam com apenas 2 ou 3 trabalhadores de uma mesma família. As de porte médio, que empregam cerca de 15 ou 20 trabalhadores; e as grandes bancas, que podem empregar uma centena de trabalhadores. De forma geral, são especializadas emrealizar determinadas tarefas que fazem parte do núcleo principal da confecção do calçado, como o corte, o pesponto etc. No Rio Grande do Sul, essas unidades produtivas são denominadas de ateliers (NAVARRO, 2006, p. 21).

2 Declaraçãode Helsinki (1975, revisada em 1983)e Resoluções do Conselho Nacional de Saúden. 196, de 10/10/96, en. 251, de $07 / 08 / 97$.

3 “A primeira fábrica de calçados do Brasil foi fundada no ano de 1888 [...],no Vale dos Sinos, interior do Estado do Rio Grande do Sul, pelo filho de imigrantes Pedro Adams Filho, que também possuía um curtume e uma fábrica de arreios." Vale dos Sinos (RS) responde por $40 \%$ da produção nacional de calçados, por $75 \%$ das exportações totais e gera quase $50 \%$ dos empregos no setor, (apudMACHADONETO, 2006,p. 60/65).

4 Segundo o Sindicato das Indústrias de Franca, o município conta atualmente com 760 empresas, sendo que destas 552 são micro empresas (que têm de 0 a 19 funcionários), 130 são consideradas pequenas (de 20 a 99 funcionários); 65 são médias (de 100 a 499 operários) e apenas 13 são consideradas grandes empresas (acima de 500 funcionários). Em janeiro de 2007 o setor contava com 20 mil postos de trabalho e com uma produção de 26,1 milhões de pares de calçados, sendo 20,8 milhões destinados ao mercado interno e 5.310.565 ao mercado externo(SINDIFRANCA, 2008).

5 “A comercialização dos calçados produzidos em Franca no mercado internacional teve início em 1969, quando a Calçados Samello S.A. realizou o primeiro embarque para o exterior. Durante a década de 1970, as exportações de calçados produzidos em Franca vão se consolidar, tornando o município o maior polo exportador de calçados masculinos de couro do país, embora o volume da produção comercializado no exterior tenha suplantado poucas vezes por aquele destinado no mercado interno"(NAVARRO, 2006,p. 146-147).

6 "O Brasil tem importante destaque na produção mundial de calçado, o setor nacional é constituído por aproximadamente 6 mil empresas, que empregam 210 mil trabalhadores, segundo as estatísticas oficiais, a capacidade instalada estimada gira em torno de 600 milhões de pares/anos, sendo $70 \%$ destinados ao mercado interno e 30\% à exportação, chegando a faturar US\$ 8 bilhões/ano. Com esses dados, o Brasil assegura a terceira posição na produção mundial de calçados, atingindo 570 milhões de pares correspondendo a $4,7 \%$ da produção mundial que em 2000 foi de 12.125 milhões depares"(LARA, 2007, p. 275). 
7 Machado Neto (2006) destaca que a China além de grande consumidora é também uma grande exportadora de calçados e que, em 2004 , teria sido a responsável por $63,8 \%$ da exportação mundial.

8 Chesnais (1996) explicita que com os avanços da teleinformática (telemática) e a sua apropriação pela empresas já não há a necessidade dessas se locomoverem de um lugar a outro, uma vez que podem terceirizar a produção e acompanhá-la por meio dos recursos da telemática. Ou seja, as novas tecnologias informacionais, microeletrônicas e de gestão das atividades e das finanças não eliminam a terceirização, mas intensificam-na.

9 Lara (2007, p. 273), relativizando Costa (1993), destaca as diferenças salariais entre alguns países produtores de calçados e infere que "[...] a produção de calçados é muito mais vantajosa em países como a Indonésia, a Tailândia, que em outros como aAlemanha, pois o salário de um trabalhador na Alemanha equivale ao salário de 13 trabalhadores na Indonésia" e conclui que isso "sem questionarmos as condições e as relações intensificadas de exploração do trabalho infantil e do feminino mal remunerado."

10 Machado Neto (2006, p. 66) explicitando o estudo do Sindifranca (2002) diz que: "O principal centro calçadista do estado é a região metropolitana de Fortaleza, onde, além da capital, sobressaem-se as cidades de Caucaia, Horizonte, Maranguape e Cascavel. No interior do estado, os destaques são as cidades de Sobral, Crato e Juazeiro do Norte, sendo que estaúltima, além de ser um polo dinâmico e relativamente consolidado no contexto estadual, é a área de maior concentração de micro e pequenas empresas calçadistas do estado do Ceará. No ano de 2002, as empresas do Estado empregavam 36,7 mil pessoas, o que correspondia cerca de $14 \%$ dos postos de trabalho no setor."

11 Sendo os EUA um dos principais destinos do sapato brasileiro é preciso pensar nos reflexos da atual crise econômica desencadeada no cenário americano, mais precisamente no mercado imobiliário, fluxo de crédito e de extrema instabilidade financeira. Esta crise resultou, entre outros, na elevação do desemprego naquele país.“[...] Os cortes de postos de trabalho em novembro [de 2008], os maiores desde 1974, indicaram que a atual recessão - que já dura 12 meses poderá ser não só a mais forte, mas também a mais longa desde a Grande Depressão.[...] E 2008 já se aproxima do recorde de cortes de emprego desde a Segunda Guerra. Só nesta semana, a empresa de Telecomunicações AT\&T anunciou o corte de 12 mil empregos; a Dupont, do setor químico, cortou 2.500 ea Viacom, de mídia, 850. A GM, lutando contra a falência, anunciou ontem que cortará mais 2.000 postos [...]'(MURTA, 2008, online).

12 Estaéumacaracterísticado setorcalçadistaemgeral. "A indústria decalçadostantoemâmbitomundial quantoemâmbitonacional é um segmento conhecido pelas seguintes particularidades: baixo investimento em inovações tecnológicas; baixo custo do produto final; uso intensivo da força de trabalho; estrutura industrial com predominância das micro, das pequenas e das médias empresas, com reduzido número de organizações de grandeporte"(LARA, 2007,p. 263).

13 Essa informação fornecidapela Prefeitura Municipal deFranca se deu por meio do pagamento antecipado de $\mathrm{R} \$ 35,00$ (LOURENÇO,2009).

14 Especificamente no período de abril de 2004 a maio de 2008.

15 Sãopoucas e falhas as estatísticas oficiais a respeito do número total de bancas de pesponto, de corte, de "blaqueação", de chanfradura etc. existentes em Franca, assim como também são falhas e poucas aquelas referentes a outras modalidades de trabalho realizado em domicílio, como a costura manual, a colocação de enfeites e "tressê" e o número de crianças envolvidas na produção de calçados no município.A facilidade de se encontrar pessoas trabalhando nessas condições no município e o reconhecimento, por parte dos empresários locais, dos sindicalistas, dos trabalhadores e demais moradores da cidade, da existência de um número elevado de pessoas envolvidas nessa modalidade de trabalho dão a entender que os números oficiais, quando existem não refletem a realidade (NAVARRO, 2006).

\section{Edvânia Ângela de Souza Lourenço}

edvaniaangela@hotmail.com

Doutorado em Serviço Social pela Universidade Estadual Paulista Julio de Mesquita Filho (UNESP), Franca

Professora do Departamento de Serviço Social da UNESP e do Instituto Municipal de Ensino Superior "Victorio Cardassi" (IMESB), Bebedouro

\section{Iris Fenner Bertani}

irisbertani1311@yahoo.com.br

Doutorado em Serviço Social pela Pontifícia Universidade Católica de São Paulo (PUC/SP)

Professora da Graduação e Pós-Graduação em Serviço Social da UNESP

Pesquisadoras do Grupo de Estudos e Pesquisas sobre Saúde, Qualidade de Vida e Relações de Trabalho (Quavisss), certificado pela UNESP e credenciado pelo CNPq

\section{UNESP - Franca}

Av. Eufrásia Monteiro Petráglia, 900

Jardim Dr. Antonio Petráglia

Franca - São Paulo - Brasil

CEP: 14409-160 